\title{
ROBÓTICA EDUCACIONAL NO BRASIL: QUESTÕES EM ABERTO, DESAFIOS E PERSPECTIVAS FUTURAS
}

\author{
ROBOTICA EDUCATIVA EN BRASIL: CUESTIONES EN ABIERTO, DESAFÍOS \\ Y PERSPECTIVAS FUTURAS
}

\section{EDUCATIONAL ROBOTICS IN BRAZIL: CHALLENGES, PERSPECTIVES AND OPEN QUESTIONS}

Flavio Rodrigues CAMPOS ${ }^{1}$

RESUMO: Este artigo investiga a situação atual do campo da robótica na educação no Brasil e identifica os desafios e questões atuais relacionados ao uso das tecnologias em robótica como ferramentas que irão dar suporte à criatividade e outras habilidades na formação do indivíduo. Com efeito, conclusões e propostas são apresentadas para promover a cooperação de pesquisadores e professores no Brasil que podem dar suporte ao desenvolvimento futuro do movimento da robótica na educação.

PALAVRAS-CHAVE: Robótica na educação. Currículo. Tecnologias na educação.

RESUMEN: Este artículo investiga la situación actual en el campo de la robótica en la educación en Brasil e identifica los desafios y cuestiones actuales relacionadas al uso de las tecnologías en robótica como herramientas que dar soporte a la creatividad y otras habilidades en la formación del individuo. En efecto, conclusiones y propuestas se presentan para promover la cooperación de investigadores y profesores en Brasil que pueden dar soporte al desarrollo futuro del movimiento de la robótica en la educación.

PALABRAS CLAVE: Robotica en la educación. Curriculo. Tecnologias en la educación.

ABSTRACT: This paper investigates the current situation in the field of educational robotics and identifies challenges and open questions focusing on the use of robotic technologies as a tool that will support creativity and other learning skills for the individual education. Therefore, conclusions and proposals are presented for promoting cooperation of researchers and teachers in Brazil that might support the further development of the robotics movement in education.

KEYWORDS: Robotics in education. Curriculum. Technology in education.

1 Serviço Nacional de Aprendizagem Comercial (SENAC), São Paulo - SP - Brasil. Pós-Doutor na Faculdade de Educação da Universidade de São Paulo (USP). Consultor Pedagógico do SENAC-SP e Diretor Escolar. E-mail: flavio.rcampos@sp.senac.br.

RIAEE - Revista Ibero-Americana de Estudos em Educação, Araraquara, v.12, n.4, p. 2108-2121, out./dez. 2017. 


\section{Introdução}

$\mathrm{Na}$ última década, a robótica tem aguçado o interesse de docentes e pesquisadores como um importante recurso para o desenvolvimento cognitivo e habilidades sociais de alunos da Educação infantil ao Ensino Médio, e no embasamento para o aprendizado de Ciências, Matemática, Tecnologia, computação e outros saberes.

Este artigo está estruturado nos fundamentos e ideias presentes nas investigações, práticas e pesquisas no campo da Robótica na Educação no Brasil, destacando-se a situação atual da área, tanto acadêmica quanto na comunidade de prática das escolas brasileiras, e examinando os caminhos possíveis no movimento da robótica na educação.

O artigo começa com uma investigação do estado da arte no campo da robótica na educação. Em seguida, apresenta os problemas atuais do campo de pesquisa e prática e novos desafios. Por fim, apresenta algumas propostas para integrar a robótica enquanto recurso tecnológico e as teorias de aprendizagem para promover a cooperação e uma rede de trabalho de pesquisadores e docentes, bem como contribuir com a comunidade da robótica na educação no Brasil.

\section{Investigação do campo da Robótica em Educação}

A revisão de literatura da área revela que a robótica educacional como campo de pesquisa e prática está crescendo, com um grande potencial para impactar a natureza da educação em ciência e tecnologia em todos os níveis de ensino, da educação Infantil à universidade. A robótica na educação notoriamente emergiu como um recurso tecnológico de aprendizagem, único que pode oferecer o "aprender fazendo", bem como atividades lúdicas em um ambiente de aprendizagem atrativo, que fomenta o interesse e curiosidade dos alunos.

As principais teorias de aprendizagem que sustentam a prática da robótica na educação são o construtivismo e o construcionismo. Piaget destaca que manipular artefatos é a chave para a criança construir seu conhecimento (PIAGET, 1974). Papert adicionou a essa equação a ideia de que a construção do conhecimento acontece de maneira efetiva em um contexto onde o aprendiz está conscientemente engajado em construir um objeto público, seja um castelo de areia na praia ou um artefato tecnológico (PAPERT, 1980). 
Embora sejam os principais expoentes, não podemos deixar de destacar o sociointeracionismo de Vygotsky, o construcionismo social e o construcionismo distribuído. Quando os membros de um espaço social desenvolvem construções sociais compartilhadas e externas, eles engajam o espaço social em um ciclo de desenvolvimento que é fundamental para determinar a transformação constante do espaço social. O seu foco está acima das ramificações de desenvolvimento inerentes na natureza social. Para o construcionismo, os ciclos de desenvolvimento individuais são realçados pelo compartilhamento de atividades construtivas no espaço social. $\mathrm{O}$ construcionismo social acrescenta que o espaço social é também realçado pela atividade de desenvolvimento intelectual do indivíduo (RESNICK, 2000).

O espaço social não é visto aqui com um lugar neutro onde o desenvolvimento de atividades intelectuais acontece, mas sim como intimamente envolvido com o processo e com o resultado do próprio desenvolvimento. Assim, este desdobramento está fundamentado no próprio construcionismo e também marcado fortemente pela presença do sócio-interacionismo de Vygotsky. O construcionismo distribuído expande a teoria construcionista, na medida em que prioriza as situações de aprendizagem onde vários aprendizes estão envolvidos, ou seja, coloca ênfase maior na questão social (Vygotsky).

O papel docente no contexto das teorias de aprendizagem em ambientes que utilizam a robótica como recurso tecnológico é de oferecer oportunidades para os alunos engajarem-se em atividades de exploração 'mão na massa' e de prover ferramentas para que eles possam construir conhecimento no ambiente de sala de aula. A robótica educacional cria um ambiente de aprendizagem no qual o aluno pode interagir no meio e trabalhar com problemas reais do seu dia-a-dia.

Estudos e pesquisas evidenciam que a robótica tem impacto potencial no aprendizado dos alunos em diferentes áreas do conhecimento (física, matemática, engenharia, computação e muito mais) e em relação ao desenvolvimento pessoal, incluindo cognição, meta-cognição e habilidades sociais, como: habilidades de pesquisa, pensamento criativo, tomada de decisão, resolução de problema, comunicação e trabalho colaborativo (EGUCHI, 2010; BENITTI, 2012).

Ao falarmos de currículo nas escolas, a robótica educacional geralmente é utilizada sob três óticas:

RIAEE - Revista Ibero-Americana de Estudos em Educação, Araraquara, v.12, n.4, p. 2108-2121, out./dez. 2017. 
- Currículo por tema: o currículo é desenhado a partir de um tema de saber específico, sendo organizado de forma disciplinar ou interdisciplinar. Nesta categoria, o currículo direciona-se para o aprendizado da robótica e sua tecnologia ou no uso da robótica para o aprendizado de conceitos de diferentes áreas do saber como, por exemplo, da física, matemática, ciências, etc.

- Currículo por projeto: o currículo é desenhado para o desenvolvimento de projetos que envolvem vários temas/conteúdos, também se caracterizando pelo aprendizado da robótica e suas tecnologias ou para o aprendizado de conceitos de diferentes áreas dos saberes.

- Currículo por Objetivo/competição: os alunos desenvolvem atividades que visam à participação em eventos e competições de robótica, trabalhando habilidades relacionadas à participação nos desafios propostos.

Podemos observar também um aumento no número de eventos e torneios de Robótica na Educação, seja no âmbito da Educação Básica, como o FLL2, seja nas universidades, com a olimpíada brasileira de robótica.

Importante destacar também o aumento nos últimos 20 anos no número de dissertações e teses3 que se empenharam em estudar a utilização da robótica no ambiente escolar formal e informal, contribuindo para a disseminação do conhecimento do campo e também colaborando com a prática de sala de aula que usa a robótica como recurso didático.

Por outro lado, não temos uma introdução sistemática da robótica no currículo escolar brasileiro, nem ao menos algo concreto em termos de parâmetros curriculares nacionais/políticas públicas em âmbito nacional. Contudo, muitas escolas e universidades estão se engajando para construir em suas realidades caminhos possíveis para integração da robótica em suas práticas de maneira significativa.

\section{Questões em aberto e desafios da Robótica na Educação}

A robótica educacional, considerada um ramo da educação tecnológica, sofre com os velhos problemas bem conhecidos quanto do uso de tecnologias na educação.

\footnotetext{
${ }^{2}$ First Lego League - Evento mundial organizado pela Lego Education primeiramente em cada país e posteriormente nas finais que geralmente acontecem nos EUA.

${ }^{3}$ Base de dados da CAPES - Coordenação de Aperfeiçoamento de Pessoal de Nível Superior.
} 
Nesta seção, destacaremos alguns problemas atuais e seus consequentes desafios para a comunidade da robótica educacional.

\section{“A Tecnologia está em todo lugar, exceto nas escolas"}

Pesquisas em todo o mundo apontam para o crescimento do mercado de robôs, incluindo aqueles usados para o entretenimento e educação, e esta tendência deve continuar nas próximas décadas (BENITTI, 2010). Embora o uso de tecnologias no cotidiano da sociedade seja visível, na educação as coisas tendem a ter um caminho mais lento e de reforço a uma prática pedagógica tradicional.

Enquanto especialistas estão otimistas quanto ao desenvolvimento de oportunidades de uso de tecnologias na aprendizagem, o ceticismo prevalece em relação à habilidade dos sistemas de educação formal e instituições em manter o ritmo da mudança e de se tornarem mais flexíveis e dinâmicas. Estas dificuldades são relevantes na medida em que observamos dados de pesquisas que apontam para o esvaziamento na busca dos alunos pelas áreas da ciência e tecnologia.

Embora tenhamos ações isoladas no setor público de incentivo ao uso da robótica na educação e escolas privadas tenham buscado na última década ampliar a seara da utilização de tecnologias na educação formal, a maioria das iniciativas envolvendo a robótica na escola não está integrada às aulas regulares do currículo, ou seja, geralmente são programas fora do horário de aula do aluno. As que optam por integrar a robótica o fazem, em sua maioria, por meio da criação de um componente curricular que lança mão de projetos/temas pré-concebidos para adequarem-se à relação tempo/espaço/material disponível.

Além dessa questão, docentes que utilizam a robótica em suas atividades geralmente destacam que os programas de robótica fora do horário regular que normalmente alcançam um pequeno grupo de alunos são mais convenientes (CAMPOS, 2011). Os obstáculos relacionados à implementação da robótica no currículo regular nos parece ser a natureza do tempo requerido para atividades de robótica, o custo do equipamento necessário e a formação teórico-prática do docente para o correto manuseio dos equipamentos, bem como da articulação teoria e prática do uso deste recurso tecnológico. Este problema parece ficar ainda pior quando levamos em conta a percepção de que a robótica, igualmente com outras áreas da ciência e tecnologia, é

RIAEE - Revista Ibero-Americana de Estudos em Educação, Araraquara, v.12, n.4, p. 2108-2121, out./dez. 2017. 
difícil, mais direcionada para um gênero (homens), e não convidativa para a maioria dos alunos (BLIKSTEIN, 2013).

É possível perceber algumas propostas nos últimos anos na direção de uma abordagem em que a aplicação da robótica pode corroborar com a tecnologia educacional e buscar o interesse dos alunos (CAMPOS, 2011). Os movimentos chamados "fabricação digital e mão na massa" (GERSHENFELD, 2007; BLIKSTEIN, 2013), com seus laboratórios "Fablabs e Espaços Makers" tem aspirado e trabalhado para superar a dicotomia inerente nos sistemas educacionais e conectar o esforço intelectual dos alunos em sala com suas experiências em "fazer" e construir coisas com seus amigos, pais e parentes em garagens, espaços não formais de educação, clubes, etc.

\section{Tecnologias nas escolas não consideram as habilidades do século XXI}

Promover a excelência na educação e o desenvolvimento de habilidades é um dos elementos-chave apontado por educadores e pesquisadores como objetivo de uma educação formal. Contudo, a educação para a ciência permanece em um estado de fraqueza em suas bases na formação do indivíduo (Bizzo, 2012), e as habilidades do futuro destacadas pela UNESCO e o desenvolvimento de cidadãos "cientificamente" ativos devem ser constituídas desde a infância, bem como as competências transversais, como pensamento criativo, resolução de problemas, criatividade, trabalho em equipe e habilidades de comunicação.

Atualmente, temos presenciado iniciativas em todo o mundo de transformar a educação que irá promover a criatividade e o sentido de invenção dos indivíduos (RESNICK, 2007). Os alunos estão crescendo em um mundo que é muito diferente do mundo de seus pais e avôs. Para ter sucesso nesta sociedade da "criatividade" (RESNICK, 2007), os alunos devem aprender a pensar criativamente, planejar sistematicamente, analisar criticamente, colaborativamente, comunicar-se claramente e aprender continuamente.

O uso de metodologias de aprendizagem apropriadas, como trabalho por projetos, abordagem por competências, aprendizagem baseada em problemas, bem como a aprendizagem cientifica, podem contribuir de maneira significativa no desenvolvimento dessas habilidades. A resolução de problemas e a aprendizagem científica têm estado em evidencia nos últimos anos nas discussões sobre os rumos da educação no país, e pode ser evidenciada nas organizações curriculares das escolas.

RIAEE - Revista Ibero-Americana de Estudos em Educação, Araraquara, v.12, n.4, p. 2108-2121, out./dez. 2017. 
Entretanto, os usos das tecnologias (incluindo a robótica) nas escolas atualmente não sustentam o desenvolvimento das habilidades do século XXI já mencionadas. Em muitos casos, o surgimento de novas tecnologias está simplesmente reforçando velhos hábitos de ensinar e aprender. Os laboratórios de tecnologia e ciências das escolas não parecem apresentar práticas que evidenciam o desenvolvimento do pensamento criativo, da resolução de problemas, criatividade, dentre outras já mencionadas, haja vista que sua arquitetura traduz uma educação rigorosa, disciplinar e segmentada, com experiências pré-determinadas nas quais os alunos são guiados normalmente por "receitas" ao invés da "descoberta" de conceitos pré-definidos.

Em sintonia com essa perspectiva, uma importante distinção emerge entre "competência técnica", necessária em conhecimento para os profissionais engenheiros e cientistas no exercício de suas funções, e "fluência tecnológica", conhecimento significativo, habilidades e atitudes valiosas para todas as pessoas (PAPERT, 1987). De acordo com as habilidades do século XXI já destacadas, o desenvolvimento atual da sociedade pede uma mudança na percepção sobre tecnologia educacional de habilidades técnicas para fluência tecnológica e computacional. Para o campo da robótica na educação, mudar-se-ia do "apenas" uso da robótica para contribuir com o desenvolvimento de habilidades vocacionais para os futuros cientistas, engenheiros, matemáticos, para uma fluência em robótica, transformando-a em vantagens intelectuais e manuais disponíveis para qualquer indivíduo.

\section{A robótica está a serviço de outros saberes? É preciso novas e amplas perspectivas}

A maneira com que a robótica está sendo introduzida e trabalhada no contexto educacional é desnecessariamente restrita. Até o momento, a maioria das utilizações das tecnologias em robótica na educação tem como foco dar suporte ao ensino de conteúdos que são próximos ao campo da robótica enquanto ciência, como a programação de robôs, construção e mecatrônica. Além disso, outra abordagem comum é utilizar a robótica no aprendizado de conceitos de áreas correlatas como a física, ciências e matemática.

Se quisermos alcançar os alunos, independente de suas aptidões, é preciso pensar em projetos mais amplos. Uma perspectiva mais abrangente quanto aos saberes e objetivos de seu uso tem potencial para engajar as crianças e os jovens com os mais

RIAEE - Revista Ibero-Americana de Estudos em Educação, Araraquara, v.12, n.4, p. 2108-2121, out./dez. 2017. 
diversos interesses. Na busca por essa perspectiva, precisamos desenvolver novas e inovadoras formas de tornar mais atrativo o desenvolvimento de projetos de robótica.

Sugerimos, nesse sentido, quatro estratégias para ampliar o engajamento dos alunos em aprender robótica:

- Projetos com foco em temas, não apenas desafios;

- Projetos que combinem arte e engenharia;

- Projetos que estimulem o desenvolvimento de histórias;

- Organização de mostras, não apenas campeonatos.

Os jovens que normalmente não se interessam pela robótica devido à forma de abordagem, contudo, podem se motivar quando as atividades são trabalhadas através de histórias (como, por exemplo, criando um show de bonecos), ou em contato com outros campos do saber e áreas de interesse, como música e arte (RESNICK, 1991). Diferentes estudantes são atraídos por diferentes tipos de atividades de robótica. Estudantes interessados em carros despertam sua motivação para criar carros motorizados, enquanto estudantes com interesse em arte ou música são mais propensos a fazer criações robóticas artísticas. (BENITTI, 2011).

Personificação é outro aspecto inovador que pode ser introduzido nas atividades de robótica para torná-las mais significativas para os alunos. Experiências de personificação com robótica podem ser percebidas quando os alunos movimentam seu próprio corpo e depois programam um robô para cumprir uma determinada tarefa. Neste caso, o aprendizado se desenvolve no uso do corpo para personificação de um substituto (Lu et al., 2011). Outra maneira de facilitar o aprendizado personificado com robótica seria fazer com que os aprendizes personifiquem o sistema robótico, por exemplo, fazendo perguntas para reencenar ou seguir movimentos dos robôs através dos gestos (DE KONING; TABBERS, 2011).

Além disso, é preciso discutir a integração do movimento “maker”, da eletrônica e aprendizagem por experimentação (tinkering) na construção do currículo e atividades de robótica na educação básica, haja vista a existência de certa "confusão" de conceitos e práticas da robótica no contexto educacional a partir da inclusão desses movimentos.

Mudar o paradigma da "caixa preta" para "caixa branca": aprendizes como "fazedores/criadores" ao invés de apenas consumidores 
A indústria da robótica, até o momento, vislumbra os humanos usando robôs pré-programados e pré-fabricados. A forma com que os robôs são feitos e programados são "caixas pretas" para seus usuários, pois a tecnologia já vem pronta, tornando-os meros consumidores. Infelizmente, o mesmo método da "caixa preta" é utilizado nos ambientes de robótica educacional, onde o robô é construído ou programado antecipadamente, sendo introduzido na atividade como um fim ou uma ferramenta passiva.

A razão para esta proposta da "caixa preta" está fundamentada na percepção de que a construção e a programação de um robô são tarefas muito complexas para uma criança. Entretanto, essas dificuldades têm sido compreendidas muito mais pela deficiência no seu design do que pelo alcance cognitivo do aluno (BLIKSTEIN, 2013). Não importa qual seja o desvio no caminho, a metáfora da "caixa preta" é compatível com o paradigma do ensino tradicional. Muito diferente desta perspectiva, as metodologias ativas requerem a transição para um design transparente, "caixa branca", dos robôs, onde os usuários podem construir e desconstruir objetos, podem programar robôs e ter acesso profundo às estruturas dos artefatos por eles mesmos ao invés de apenas consumir tecnologias prontas. A metáfora da "caixa branca" para a construção e programação pode contribuir com o pensamento criativo e o engajamento dos alunos (RESNICK; BERG; EISENBERG, 2000).

Contudo, muitos alunos não conseguem progredir de certo ponto na programação e também na construção do dispositivo robótico em muitos de seus projetos. Portanto, o compromisso com a transparência no design de kits de robótica para o contexto educacional tem sido sugerido no meio acadêmico e industrial, o que resulta nessa chamada perspectiva da "caixa preta e branca", para que as crianças e jovens possam engajar-se em atividades construcionistas significativas, interessantes e desafiadoras por meio do controle de dispositivos robóticos ou de seu ambiente.

Isso é possível verificar quando os docentes desejam ter o foco na programação em suas aulas sem ter tempo hábil na construção dos robôs. Assim, os docentes precisam ter em suas aulas robôs pré-construídos para que possam ganhar tempo nas atividades e para que os alunos tenham tempo suficiente para trabalhar a programação e o controle do dispositivo criado de uma maneira clara e objetiva. Por último, o dilema entre a metáfora da "caixa branca" e a "caixa preta" deveria ser respondido por educadores e docentes de acordo com seus objetivos de aprendizagem quando eles 
introduzem robótica em suas aulas e, mais importante, de acordo com os interesses e necessidades dos alunos.

\section{A robótica é só um modismo? Necessidade de validarmos o impacto da Robótica no Ensino e na Aprendizagem}

Está claro que, enquanto a robótica tem demonstrado potencial positivo no contexto educacional, ela não é só um remédio para os problemas da educação. $\mathrm{Na}$ literatura existem estudos destacando que o uso da robótica não teve impacto na aprendizagem dos alunos em alguns casos (BENITTI, 2011). De qualquer forma, o impacto da robótica em promover a aprendizagem e o desenvolvimento de habilidades precisa ser validado através de evidencias em pesquisas. Sem essa validação, as atividades de robótica podem configurar-se como um modismo, mais uma ferramenta a serviço de velhas práticas pedagógicas. Entretanto, existe uma fissura em termos de avaliações sistemáticas e experiências de design na robótica educacional.

Na comunidade de pesquisa sobre robótica em educação, é crescente a crítica sobre a falta de investigação quantitativa em como a robótica pode melhorar o aprendizado dos alunos. Apontamos a falta de um exame sistemático dos projetos de robótica e de uma avaliação significativa dos impactos, ou se alcançam seus objetivos. Em alguns casos, os benefícios esperados não são claramente mensurados e definidos por causa da não existência de um sistema de indicadores e de uma metodologia padrão de avaliação para eles (ORTIZ; BUSTOS; RIOS, 2011). Apesar dos benefícios de seus aspectos educacionais e motivacionais, estudos sugerem que pesquisas quantitativas rigorosas estão faltando na literatura sobre a robótica no contexto educacional.

Pesquisas envolvendo a robótica na sala de aula normalmente fornecem resultados relacionados à percepção dos estudantes ou docentes, ao invés de promover o design rigoroso de pesquisas baseadas nos dados de realização dos alunos. As pesquisas precisam destacar em qual projeto de robótica ou curso os objetivos de aprendizagem foram alcançados, se mais alunos demonstram interesse em ciência e tecnologia ou se desenvolvem de maneira significativa por meio da robótica as habilidades cognitivas ou sociais. Soma-se a isso a necessidade de investigarmos se a robótica no contexto educacional na educação infantil e séries iniciais do ensino fundamental tem impacto em suas futuras carreiras profissionais, qual requer projetos de avaliação longitudinal. 
Contudo, durante uma aula de robótica os alunos trabalham desenvolvendo seus projetos ou na resolução de problemas tomando caminhos diversos e imprevisíveis, tornando difícil para os avaliadores seguir o progresso dos alunos. O monitoramento de ambientes tem sido proposto para permitir ao docente monitorar e modelar o processo de aprendizagem fundamentado em dados providos da avaliação da situação de aprendizagem. Essa mineração de dados mostra-se promissora na coleta e tratamento de dados mais efetivos quanto da prática da robótica no contexto educacional e acadêmico.

Temos um importante aspecto a considerar sobre a robótica; a articulação entre a área de computação e educação. Não será possível fomentar propostas e práticas educativas concretas sem a integração da área de computação (robótica) com a educação (pedagogia e licenciaturas). Isso porque na formação do educador não contemplamos a articulação dos saberes técnico-operacionais dos materiais de robótica disponíveis, bem como os saberes didático-pedagógicos. Como exemplo, os cursos de Pedagogia precisam considerar a construção de saberes voltados à robótica educacional, pois é comum o uso da robótica como recurso tecnológico nas escolas de educação básica, e os docentes formados em pedagogia são os responsáveis pela turma, mesmo que a instituição tenha docentes específicos que orientem o trabalho de sala de aula. Nesse sentido, é importante considerar na formação do educador (licenciaturas - matemática ciências - química - computação, pedagogia) um currículo que permita ao futuro docente articular teoria e prática da robótica educacional, proporcionando reflexão quanto ao currículo e os saberes didáticos e técnicos que envolvem a utilização deste recurso em sua prática.

Portanto, tanto o campo da computação quanto a educação precisam unir forças com o intuito de não apenas discutir e propor ações técnico-operacionais do uso da robótica na prática educativa ou de refletir sobre o impacto deste uso na escola, mas de ampliar o escopo da integração desta tecnologia a fim de possibilitar estudos mais aprofundados sobre currículo, didática e tecnologia.

\section{Considerações finais}

A partir do que foi exposto fica evidente a necessidade de repensarmos a prática e pesquisa em robótica na educação. A robótica tem muito potencial a oferecer à educação, entretanto, os benefícios à aprendizagem não são garantidos aos estudantes com a simples introdução da robótica em sala de aula, já que existem vários fatores que

RIAEE - Revista Ibero-Americana de Estudos em Educação, Araraquara, v.12, n.4, p. 2108-2121, out./dez. 2017. 
determinam esses resultados. Os robôs não são o recurso para melhoria da aprendizagem, pois a questão essencial não é o recurso tecnológico em si, mas o currículo. A robótica é mais um recurso, sendo o currículo que irá determinar o resultado da aprendizagem e a sincronia da tecnologia com as teorias de aprendizagem.

Uma proposta educacional adequada, o currículo e um ambiente de aprendizagem são alguns dos importantes elementos que podem direcionar a inovação no campo da robótica educacional. É necessário, portanto, mudar o foco da tecnologia para o desenvolvimento de currículo, pois acreditamos que o currículo seja elementochave na robótica educacional e é imprescindível incorporar os princípios da aprendizagem e determinar métricas qualitativas e quantitativas para os resultados esperados e para validação do currículo. O papel da robótica no contexto educacional deveria ser de um recurso para fomentar habilidades essenciais para a vida (desenvolvimento cognitivo e pessoal, trabalho em equipe), as quais as pessoas possam desenvolver seu potencial para usar a imaginação, para expressarem-se e tomar decisões valiosas em suas vidas. Os benefícios da robótica são relevantes para as crianças e os jovens; a robótica deve ser usada por todos na escola, não apenas os que demonstram maior interesse em ciência e tecnologia.

Nesse sentido, uma perspectiva mais abrangente se faz necessária para fomentar habilidades criativas para todas as crianças e jovens, independente da orientação escolar ou gênero. Apresentar diferentes estratégias para introduzir aos alunos as atividades de robótica e seus conceitos deve ser mandatório por parte de educadores e docentes com o intuito de promover múltiplos caminhos de imersão ao universo da robótica, abrindo espaço às crianças e jovens com interesses e estilos de aprendizagem diversos (D’abreu, 2011). Um planejamento interativo de ações se faz necessário para que haja validação das diferentes estratégias e metodologias pelos quais implementações de currículos de robótica são constituídos na prática, fundamentados por estudos4, refinamentos e melhorias contínuas.

Para tanto, é preciso ter uma comunidade ativa de pesquisa e prática em robótica educacional no Brasil que irá promover uma rede de pesquisadores, educadores, gestores e alunos. Atualmente, a comunidade de pesquisa em robótica na educação ainda demonstra limitações em seu alcance em pesquisa e prática, bem como a ausência

${ }^{4}$ Estes estudos devem se estruturar em um sistema de indicadores e um padrão metodológico de avaliação, proporcionando assim a verificação dos benefícios reais.

RIAEE - Revista Ibero-Americana de Estudos em Educação, Araraquara, v.12, n.4, p. 2108-2121, out./dez. 2017. 
de eventos e workshops mais específicos nas universidades do país. A organização mais apurada desta comunidade poderá contribuir para os seguintes objetivos:

- Criar e compartilhar produtos tecnológicos e educacionais abertos e suas práticas (currículo e recursos) para educação formal e informal, refletindo na melhor escolha de prática pedagógica;

- Promover uma rede de comunicação e colaboração entre pesquisadores, educadores e alunos para troca de experiências, produtos e conhecimento;

- Para encorajar e dar suporte a implementações práticas de robótica no currículo;

- Para promover a formação inicial e continuada de docentes, tanto técnica quanto pedagógica;

- Para testar e validar o currículo e as metodologias na formação do educador e em sala de aula;

- Em promover referência para o poder público, para a academia, educadores, pais e alunos sobre os mais recentes desenvolvimentos da robótica educacional.

\section{REFERÊNCIAS}

BENITTI, F. B. V. Exploring the educational potential of robotics in schools: a systematic review. Computers \& Education, v. 58, n. 3, p. 978-988, 2012.

BIZZO, N. Pensamento Científico: a natureza da ciência no ensino fundamental. São Paulo: Melhoramentos, 2012.

BLIKSTEIN, P. Digital fabrication and "making" in education: The democratization of invention. In: WALTER-HERRMANN, J.; BOCHING, C. (Org). FabLabs: of machines, makers and inventors. p. 1-21. Bielefeld: Transcript Publishers, 2013.

CAMPOS, F. Currículo, tecnologias e robótica na educação básica. Tese de Doutorado. Programa Educação: Currículo - PUC SP, 2011.

D’ABREU, J. V.; MIRISOLA, L. G. B.; RAMOS, J. J. G. Ambiente de Robótica Pedagógica com Br. GOGO e Computadores de Baixo Custo: uma contribuição para o ensino médio. Anais do XXII SBIE - XVII WIE, 2011.

DE KONING, B. B.; TABBERS, H. K. Facilitating understanding of movements in dynamicvisualizations: an embodied perspective. Educational Psychology Review, v. 23, p. 501-521, 2011. 
EGUCHI, A. What is educational robotics? Theories behind it and practical implementation. In: GIBSON, D.; DODGE, B. (Org.). Proceedings of Society for Information Technology \& Teacher Education International Conference, 2010. p. 4006-4014. Chesapeake, VA: AACE, 2010.

GERSHENFELD, N. Fab: the coming revolution on your desktop - From personal computers to personal fabrication. NY: Basic Books, 2007.

LU, C. M.; KANG, S.; HUANG, S. C.; BLACK, J. B. Building student understanding and interest in science through embodied experiences with LEGO robotics. In:

BASTIAENS, T.; EBNER, M. (Org.). Proceedings of World, 2011.

PAPERT, S. Mindstorms: computers, children and powerful ideas. NY: Basic Books, 1980.

PAPERT, S. Computer criticism vs. technocentric thinking. Educational Researcher, v. 16, n. 1, p. 22-30, 1987.

PIAGET, J. To understand is to invent. N.Y.: Basic Books, 1974.

RESNICK, M., BERG, R.; EISENBERG, M. Beyond black boxes: bringing transparency and aesthetics back to scientific investigation. Journal of the Learning Sciences, v. 9, n. 1, p. 7-30, 2000.

RESNICK, M. Sowing the seeds for a more creative society. Learning \& Leading with Technology, v. 35, n. 4, p. 18-22, 2007.

ORTIZ, J.; BUSTOS, R.; RIOS, A. System of indicators and methodology of evaluation for the robotics in classroom. Proceedings of the 2nd International Conference on Robotics in Education. RiE 2011. p. 63-70. Vienna, Austria: Austrian Society for Innovative Computer Sciences. Disponível em: <http://www.innoc.at/fileadmin/user_upload/_temp_/RiE/Proceedings/37.pdf,2011>. Acesso em: 06 dez. 2017.

\section{Como referenciar este artigo}

CAMPOS, Flavio Rodrigues. Robótica educacional no Brasil: questões em aberto, desafios e perspectivas futuras. Revista Ibero-Americana de Estudos em Educação, Araraquara, v. 12, n. 4, p. 2108-2121, out./dez. 2017. Disponível em: <http://dx.doi.org/10.21723/riaee.v12.n4.out./dez.2017.8788>. E-ISSN: 1982-5587.

Submetido em: 05/07/2016

Aceite em: 01/07/2017 